\title{
THE RELATIONSHIP BETWEEN BUILT ENVIRONMENT AND WALKING FOR DIFFERENT TRIP PURPOSES IN PORTO ALEGRE, BRAZIL
}

\author{
A. M. LARRAÑAGA \& H. B. B. CYBIS \\ Federal University of Rio Grande do Sul, Industrial and Transportation Engineering Department, Brazil.
}

\begin{abstract}
Measures to encourage non-motorized transport have received increasing attention among congestion mitigation strategies. This paper examines the relationship between walking trips in Porto Alegre and attributes of the built environment, analyzing the effect of trip purpose. To do so, binomial logit models were estimated. Variables were stratified according to mode (motorized and walking trips) and according to trip purpose: work, study and others. Independent variables considered in this research include population density, land use, street design, accessibility of shops and service, and accessibility of public transport and parking supply. This study shows that the effect of urban characteristics depends mainly on the purpose of the trip. On work and study trips, socioeconomic variables have greater predictive power in explaining the decision to walk than the built environment variables. However, on other purpose trips, built environment variables were shown to be stronger predictors. Neighborhoods with mixed land use, grid street networks and shops/services close to households encourage walking for recreational and shopping purposes, whereas free public parking and transit availability discourage this mode.
\end{abstract}

Keywords: Built environment, walking, travel behavior, pedestrian.

\section{INTRODUCTION}

The relationship between built environment and travel behavior has been studied since the 1980s, and there is growing recognition that changes in the characteristics of the built environment can have significant impact on the travel behavior. Surveys conducted in developed countries and particularly in the United States [1-7] suggest that people living in pedestrian-oriented neighborhoods, characterized by mixed land use, high street connectivity and high population density are encouraged to drive less and use other modes of transport such as public transport, cycling and walking. This evidence supports policies to promote changes in land use to influence changes in travel behavior.

Do these observed relationships between built environment and travel behavior remain in developing cities, such as Porto Alegre, Brazil? Is the impact the same for all trip purposes? This relationship may be different than the one exposed to in American literature due to differences in the nature of built environment, cultural values and a significant increase in motorization.

Porto Alegre, capital of the southernmost state of Brazil, Rio Grande do Sul, city with a population of 1,41,000 inhabitants, has experienced a growth in its urban population and car ownership, which led to an important increase in the number of car trips $[8,9]$. Traffic congestion has increased in space and time and has become one of the most serious urban problems.

The growth process is different from that occurred in Europe and United States. In Porto Alegre, the sprawl occurred in a disorderly way and was not adequately controlled or planned by the public administration, resulting in improvised shelters for people with low income. In this process of urban expansion, the low-income population sees the periphery as a possibility of housing at a lower cost. But these regions, lack public services and infrastructure (sewers, street paving, storm water runoff, etc.) as well as superstructure (schools, health centers, public transportation, garbage collection, 
among others). The shortage of public services in the periphery leads to the necessity of traveling to access such services, increasing dependency on motorized modes. It is only in the last few decades that it has been possible to observe the emergence of gated communities for middle- and highincome class in the outskirts of the city, who seek better environmental quality [10].

Commuter trips that used to occur from neighborhoods to the center now occur in multiple directions.

Thus, the relationship between built environment and walking observed in other cities may not be significant in Porto Alegre. Still, the effects of these changes may be different. Using data from a household survey conducted in Porto Alegre, this article presents new evidence of a relationship between the built environment and utilitarian walking behavior in developing countries. This work was built upon most previous studies by stratifying trips by purpose. Trips were categorized into: (i) work trips; (ii) study trips and (iii) other trip purposes. Work trips include trips from home to work. In the case of people who, by virtue of their occupation, are constantly traveling (e.g. postmen, drivers, sellers, etc.), it was considered as work trips, i.e. only trips between home and workplace. Study trips include trips to schools, colleges, private lessons and other courses. The latter includes recreational, shopping, health and personal business trips.

The three classes of trips adopted were based on the characteristics of the activities to be performed and their possible relation to built environment. The first two classes correspond to mandatory activities and the last one to discretionary activities. The location of the work can be considered fixed in the short term, and the demand for working trips is inelastic. The choice of school locations is more flexible, and the demand for study trips may be elastic. Individuals may choose one school over another based on particular characteristics of the school itself, e.g. quality and cost, and also based on built environment attributes, such as accessibility, proximity, aesthetic, etc. The trips classification adopted in this study assumes that the effect of urban characteristics on individuals' walking decision could be different.

\section{BUILT ENVIRONMENT VARIABLES}

The influence of built environment on travel behavior is usually analyzed by the principal characteristics or dimensions that begin with letter ' $D$ '. Originally, the built environment was expressed through three dimensions proposed by Cervero and Kockelman [11], known as '3Ds': density, diversity and design. Density refers to the intensity of land use for housing, employment and other purposes. Diversity reflects the degree of heterogeneity of land use. Design refers to the street network characteristics and also to the quality of the environment for walking. Subsequently, two dimensions were added [5], distance to transit and destination accessibility, forming the '5Ds'. Distance to transit reflects the accessibility to public transport. Destination accessibility measures the easiness of accessing different types of destination (employment, education, health and shopping). Demand management, including parking supply and costs, is a sixth dimension, included in a few recent studies [5].

Each dimension can be characterized by different variables. Density is always measured by a ratio of the variable of interest and the unit area. The area can be either gross or net. The gross area considers the total area of the unit of analysis. The net area considers the built up area, excluding roads, public spaces, parks and not buildable surface. It represents how efficiently the land is used in a certain area. In the case study of pedestrian travel, the size and quantity of streets, parks and public areas influence the quality of the pedestrian environment; thus, the gross area is a better measure [12]. The variable of interest may be population, employment or households. There is a synergistic relationship between population and employment. Sometimes, both are added to calculate activity density per unit of area. For most authors, high-density neighborhoods are characterized by a high 
concentration of activities [11]. This allows an approximation of origins and destinations, increasing the opportunities to use non-motorized modes to perform daily activities. Several studies, such as those conducted by Boarnet et al. [13], Chatman [14], Ewing et al. [15], Frank et al. [16], Naes [17] proved the existence of a positive effect of density on promoting walking.

Measures of diversity in land use reflect the distribution of land uses in a given area. Krizek [12] separates the evaluation measures of the diversity of land use into three groups: (i) inspection, (ii) employment, (iii) dissimilarity index/entropy. Inspection measures involve checking the types of land use in situ. Many studies use a binary variable that indicates the presence or absence of non-residential uses in a neighborhood [18-20]. Other studies use employment data as a proxy for land use mix. These studies use data about the number of commercial establishments, number or density of retail, or number of employees [21-23]. The index of dissimilarity and entropy assess the diversity of land use. The entropy index evaluates the balance in the distribution of land use within a given area. It generates a value between 0 and 1, assuming 0 when the land use is homogeneous and 1 when the zone is occupied by equal percentages of all considered uses. The index of dissimilarity evaluates the intensity of different uses within the area. This measure requires segmentation of the cell area and involves comparing land use in neighboring cells. This index has been used in some studies, as in Cervero and Kockelman [11]. They present a disaggregated level and also show some difficulty in obtaining data. Among these measures, the entropy index is the most widely used. Studies show that more heterogeneous areas induce the realization of nonmotorized trips [16, 24, 25].

Design includes the physical characteristics of the street network within a region. The street network can present grid-like street patterns, or submit a configuration with curves. To measure the street pattern, researchers often observe the nature of the intersections. Gridded streets patterns are represented by a high number of four-way intersections in contrast to ' $\mathrm{T}$ ', or three-way intersections or cul-de-sacs. Still, the researchers analyzed the density of intersections in the analyzed region. Gridded streets in superblocks, with long distances between intersections, frequently do little to promote walking. They may actually attract car and foster high speeds [12]. Thus, measures often used for urban design are the percentage of four-way intersections, the number of intersections per unit area and the average block size. Several studies, such as those conducted by Boarnet et al. [13] and Ewing et al. [15], found that regions with a high percentage of intersections in ' $X$ ', or four-way intersections (in contrast to ' $\mathrm{T}$ ' or three-way intersections) stimulate walking. Still, many studies have found that areas with high density of intersections favor walking [13, 15, 16, 24]. Urban design is, occasionally, also measured by variables that reflect the quality of the pedestrian environment [5]. Some of them are safety, comfort, presence of sidewalks, trees, aesthetics, continuity of sidewalks and illumination.

Distance to transit is usually measured by the average distance from home to the bus stop or subway station nearest. It can also be measured by the number of stops or stations per unit area or density of public transport routes [5].

The destination accessibility measure may be regional or local. Some studies measure the regional accessibility by the distance to the closest shopping center/administrative. Others are quantified by the number of jobs, shops or attractions reachable within a certain distance or time. The local accessibility is measured by the distance from home to the nearest shop [5].

In the context of built environment and travel literature, demand management refers mostly to parking management. Parking managements are strategies to manage travel demand by changing the supply, price and utilization of parking. This dimension can be measured as the space available for public parking, paid or free private and paid. This dimension is included in a few studies [5]. 


\section{METHODOLOGY}

\subsection{Sample}

This paper uses data collected from the last origin-destination household survey conducted in Porto Alegre [26]. The data collected used in this study are from residents of four neighborhoods in Porto Alegre: Centro/Cidade Baixa and Petrópolis/Bela Vista. Figure 1 shows the location and images of some of the selected neighborhoods.

The Centro and Cidade Baixa, located downtown and in a nearby area, is characterized by a high concentration of shops, services and cultural activities. The Bela Vista and Petrópolis neighborhood are considered two of the most elegant and highest income level areas of the city, with sophisticated real estate, beautiful landscaping and parks heavily frequented by its residents. This area presents a low concentration of shops and services. These regions were selected because they present the highest and lowest percentages of walking trips compared with the total trips originated in the region. According to the survey, practically half of the trips originated in the neighborhoods Centro and Cidade Baixa were walking trips. For the Petrópolis and Bela Vista region, walking accounted for only $10 \%$ of the trips.

The data collected for these regions resulted in 1523 respondents, corresponding to 709 households. The sampling rate considered in the survey, to determine the households and the number of
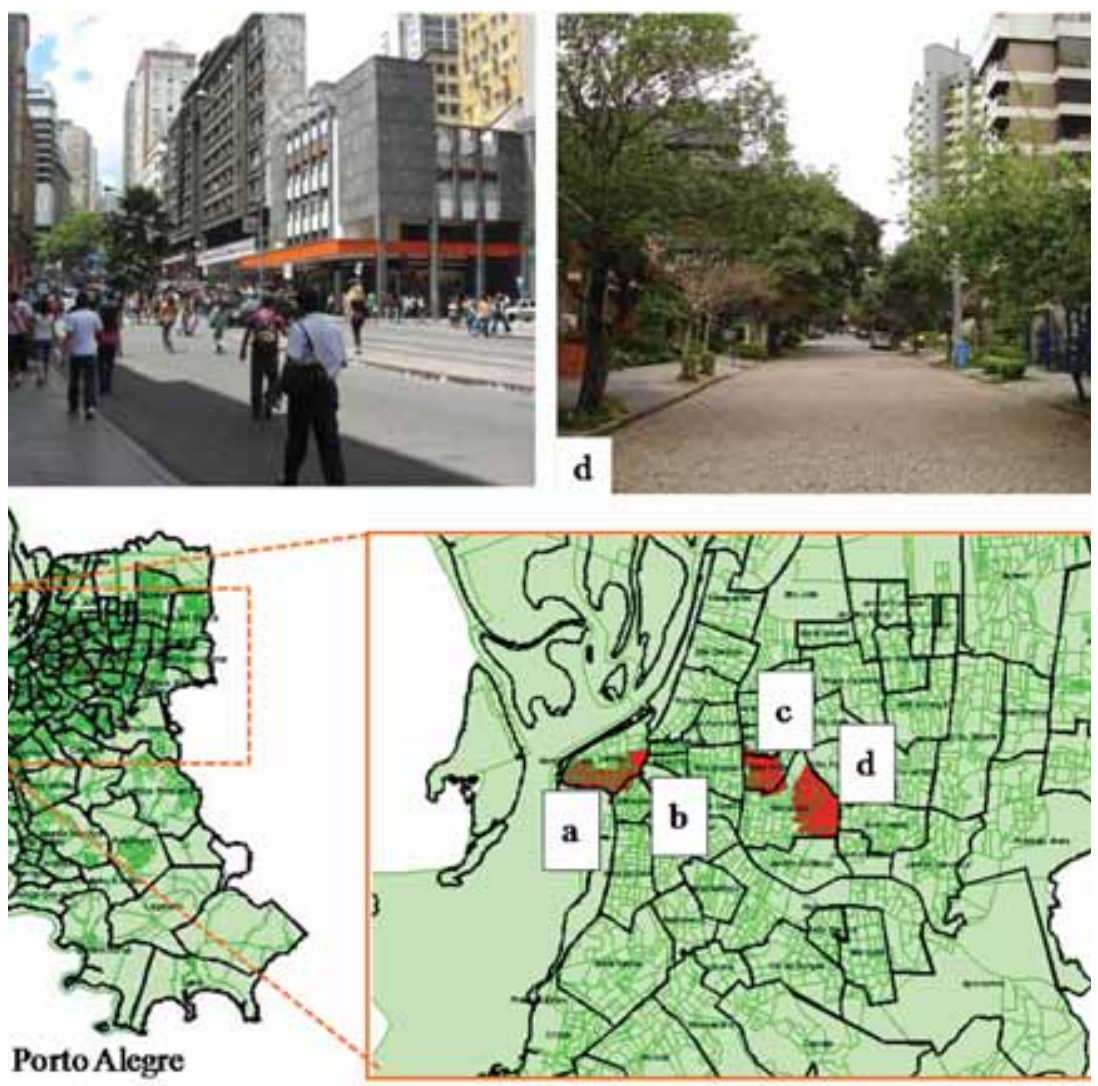

Figure 1: Selected neighborhoods in Porto Alegre. Images from Bela Vista and Centro. 
residents, was approximately $4 \%$. The survey administered provides expansion factors for the respondents, based on the household size, gender and age of residents. These factors were used in this study. Therefore, a total number of 29,041 trips were analyzed. The database includes information about socio-economic characteristics and trips taken by residents (see [26] for details). The questionnaire was divided into four sections and each one dealt with:

1. Identification of the interviews.

2. Socioeconomic characteristics of the families (e.g. income, number of cars).

3. Socioeconomic characteristics of individuals (e.g. age, gender).

4. Trips overtaken the day before.

Figures 2 and 3 present the distribution of the respondent by neighborhood. Figure 2 characterizes the sample regarding age and Fig. 3 regarding gender.

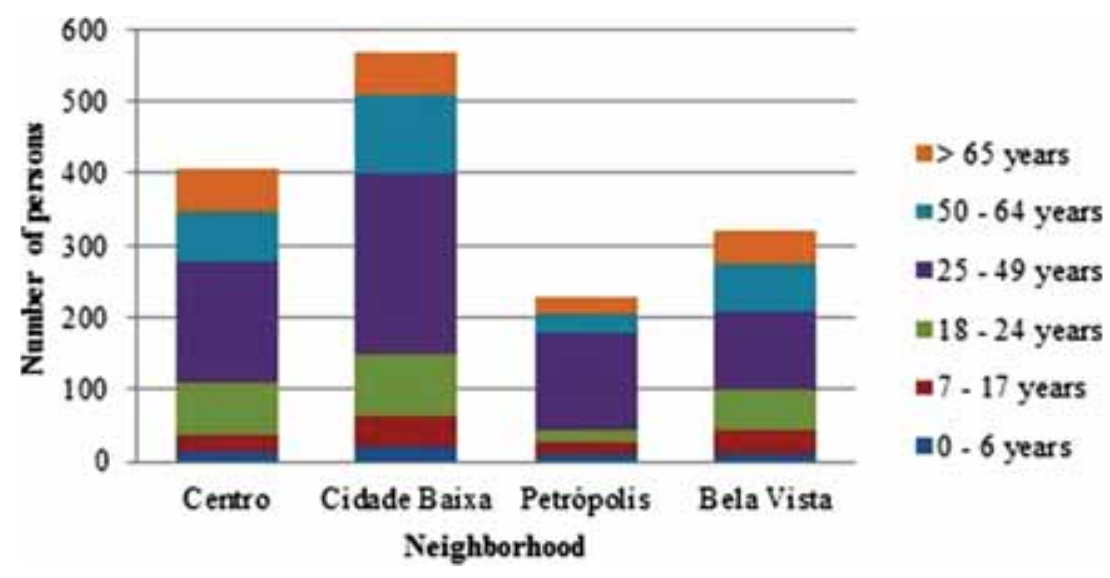

Figure 2: Distribution of respondents by age and neighborhood.

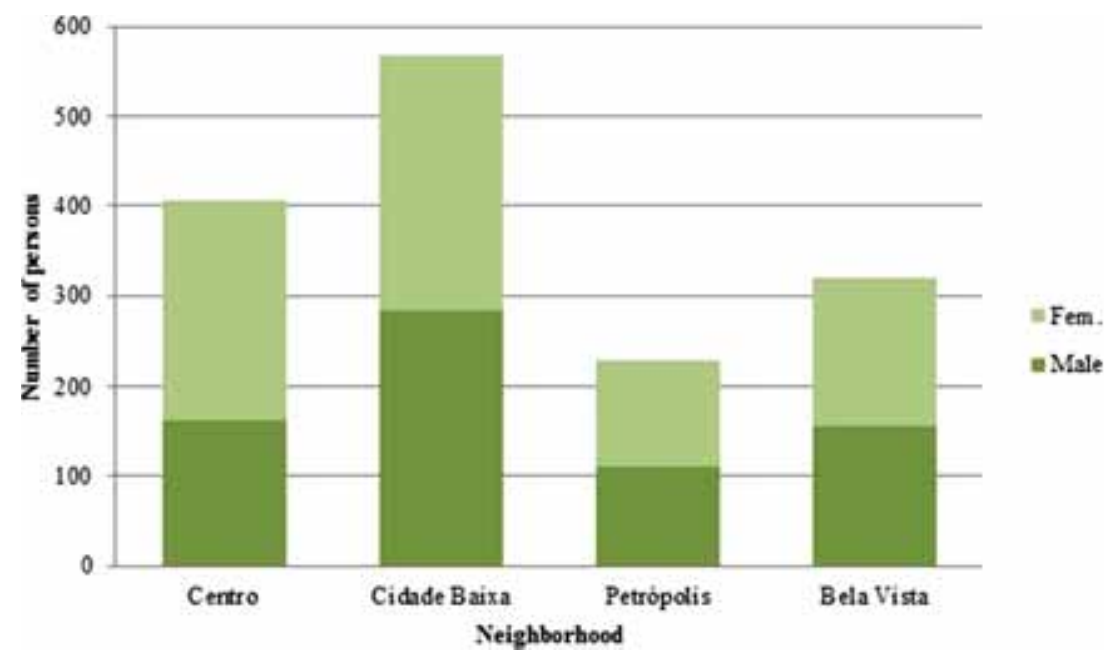

Figure 3: Distribution of respondents by gender and neighborhood. 
The determination of the unit of analysis was based on a combination of two factors: the overall goal of the work and the nature of the available data. Built environment variables should be measured on a scale sensitive to pedestrians and its aggregation should allow differences between different areas to be pointed out. Thus, the unit of analysis used was census tract.

\subsection{Variables and models}

About $95 \%$ of walking trips are shorter than $2 \mathrm{~km}$ in the city of Porto Alegre [26]. Therefore, the study considered only trips shorter than $2 \mathrm{~km}$, made by different modes of transport. Modal choice is represented as a binary variable: motorized or walking. There were no bicycle trips reported in the studied areas.

The predictor variables were divided into three categories: (i) those socioeconomic, related to individuals and their families, (ii) those related to neighborhoods and (iii) those related to the trip. Socioeconomic attributes of individuals (age and gender) and their families (income and car availability) were obtained from the responses to a household survey conducted in Porto Alegre [26]. Attributes of the neighborhoods were obtained from different sources, processing the data through geographical information system. Travel attributes (purpose and distance) were generated from trip-reported information on the household survey.

The influence of built environment on travel behavior was analyzed using the extended ' $6 \mathrm{Ds}$ ' model $[5,11]$ : density, diversity, design, distance to transit, destination accessibility and demand management. Each dimension of the built environment was characterized by different variables that were measured for a 500-m ring-buffer around the centroids of each of the selected census tracts. Figure 4 shows an example of 500-m buffers around the centroid of two sampled census tract in Porto Alegre.

Density was measured by accounting the dwelling units and inhabitants per land area $\left(\mathrm{km}^{2}\right)$. Diversity was measured in situ. The areas were classified as mixed or not by inspection, as performed by other studies [18]. Due to lack of data, it was not possible to adopt analytical techniques such as Entropy or dissimilarity index [11] to qualify diversity. The classification assigned to the land use was: (i) residential, (ii) job concentrator and (iii) mixed. The census tract was defined as residential when most units within a 500-m ring-buffer are intended for multifamily and singlefamily dwelling. The sector was defined as a job concentrator when most units are intended to run industrial or commercial activities, or institutional services. The mixed-use sector is the one that has more than one use, in a homogeneous proportion. Analyzing the database, it was observed that no sector accounted only for residential use, so the diversity of land use was defined by a binary variable. This variable assumed the value 1 , when the census track is job concentrator, and 0 , when the census tract has mixed use.

Design was measured by observing the nature of the intersections: four-way intersections, representing gridded street patterns, in contrast to ' $\mathrm{T}$ ', or three-way intersections and the intersection density, by the measure of the block size.

Distance to transit was measured by the Local Index of Transit Availability (LITA), developed by Rood [27], which includes three components: frequency, capacity and route coverage. The frequency score measures the number of available transit vehicles for the zone

$$
\mathrm{F}=\Sigma \mathrm{t}_{\mathrm{L}}
$$

where $\mathrm{F}$ is the frequency and $\mathrm{t}_{\mathrm{L}}$ is the number of trips per day of each line serving the zone, considering lines with more than one stop in the zone. 


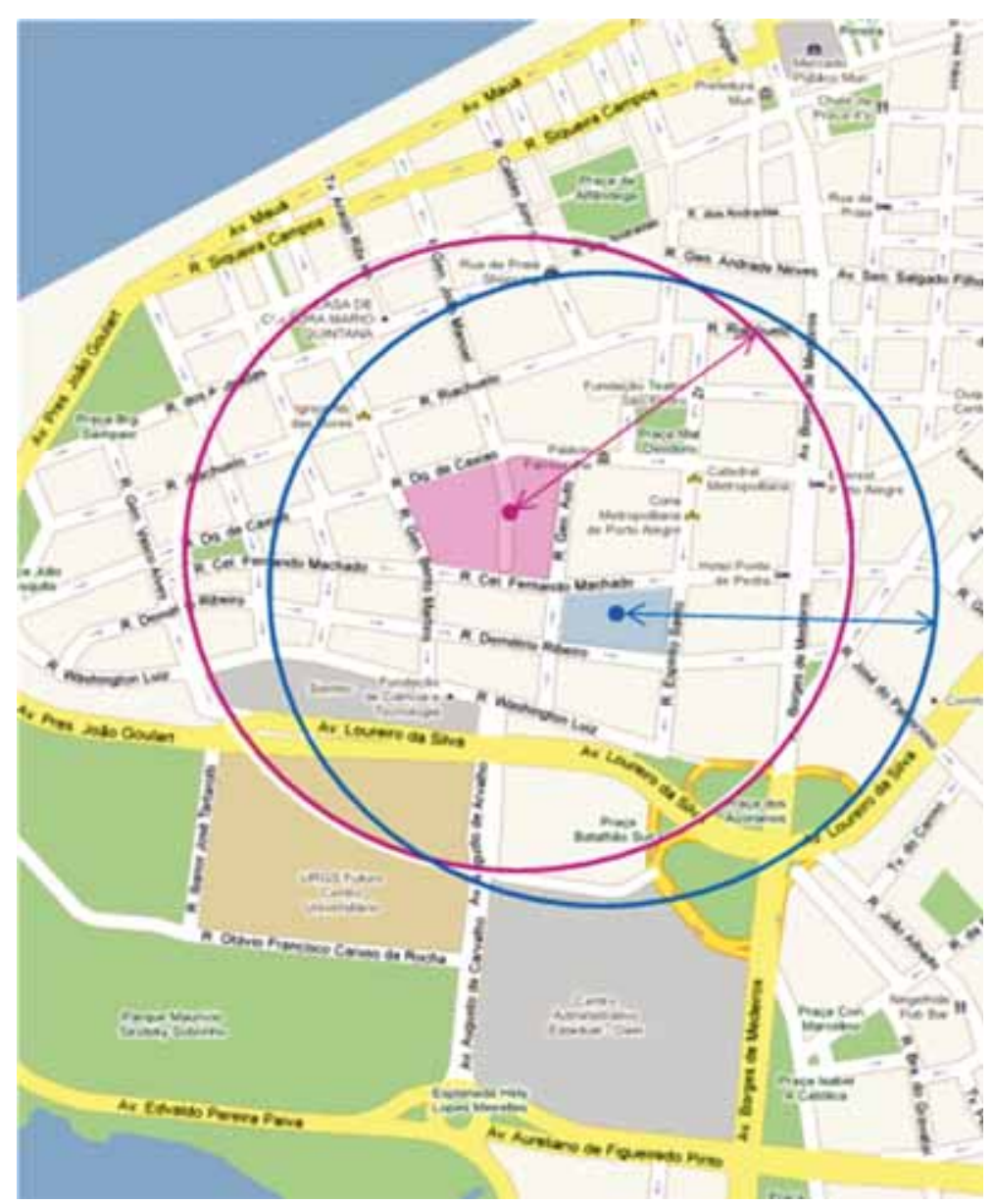

Figure 4: Example of 500-m buffers around the centroid of two sampled census tract in Porto Alegre.

The route coverage score incorporates the available number of stops in a zone and the land area of this zone

$$
\mathrm{Co}=\Sigma \mathrm{s}_{\mathrm{L}} / \mathrm{A}
$$

where Co is the coverage, $s_{\mathrm{L}}$ the number of stops of each line serving the zone and $\mathrm{A}$ the land area of the zone.

The capacity score includes the comfort and convenience aspect. This measure incorporates the daily available seats of the transit service, route miles of transit line and the total population of the area

$$
\mathrm{Ca}=\Sigma \mathrm{a}_{\mathrm{L}} \mathrm{d} / \mathrm{P}
$$

where $\mathrm{Ca}$ is the capacity, $\mathrm{a}_{\mathrm{L}}$ the daily available seats of the transit service, $\mathrm{d}$ the route miles of transit line in the zone and $\mathrm{P}$ the total population of the area. 
Each of these three scores is then standardized across all the zones in the study area to provide a measure of relative accessibility. The overall LITA score is the average of the three standardized scores

$$
\text { LITA }=\frac{\left(\mathrm{F}-\mu_{\mathrm{F}}\right) / \sigma_{\mathrm{F}}+\left(\mathrm{Co}-\mu_{\mathrm{Co}}\right) / \sigma_{\mathrm{Co}}+\left(\mathrm{Ca}-\mu_{\mathrm{Ca}}\right) / \sigma_{\mathrm{Ca}}}{3}
$$

where $\mu_{\mathrm{i}}$ is the mean of each component and $\sigma_{\mathrm{i}}$ is the standard deviation of each component.

Most studies have used simpler measures to analyze this dimension, such as distance to the bus stop or subway station or the number of stops/stations nearby per unit area [5]. These measures address the spatial availability of transit service, if transit service is located near or too far away from a potential user. However, they do not account for temporal availability and comfort. If transit service does not run at the times, a user requires it to or if the service is always full, that user would not consider transit service to be available and thus the quality of service would be poor. These measures may be appropriate to other cities, but not to Porto Alegre, which has a dense network of bus lines. This study tried to improve the representation of this dimension, paying attention also to the temporal, comfort and convenience aspects of transit service. The LITA measures the transit service intensity, or transit accessibility in an area by integrating three aspects of transit service: route coverage (spatial availability), frequency (temporal availability) and capacity (comfort and convenience) [27].

Destination accessibility was measured by accounting the existing number of shops and services in a 500-m ring-buffer. Demand management (parking supply) was measured in situ by inspection, using a binary variable indicating the presence or absence of public pay parking within a neighborhood.

Table 1 lists the candidate variables considered for model entry for each of the 6Ds.

The database, consisting of the above-described variables, was used in the estimation of binomial logit models to predict the probability of using the walk mode. The trips were stratified by: work trips, study and other purposes. The latter includes recreational, shopping, health and personal business trips. Table 2 presents the trip distribution by purpose and mode analyzed.

Table 3 presents descriptive statistics for the independent variables employed in the models. The models for the three categories of trips were estimated by SPSS software, version 18.0 [28].

Table 1: Candidate variables for six built environment dimensions, measured at the neighborhood $(500 \mathrm{~m})$.

\begin{tabular}{ll}
\hline Dimension & \multicolumn{1}{c}{ Candidate variables } \\
\hline Density & $\begin{array}{l}\left.\text { Housing density (no. dwelling units per } \mathrm{km}^{2}\right) \\
\left.\text { Population density (no. inhabitants per } \mathrm{km}^{2}\right)\end{array}$ \\
Diversity & Land use mix $(1=$ job concentrator area, $0=$ mixed) \\
Design & Blour-way intersections \\
& Transit availability(LITA) \\
Distance to transit & No. shops and services \\
Destination accessibility & Parking $(1=$ public paid, public free) \\
Demand management &
\end{tabular}


Table 2: Trip distribution.

\begin{tabular}{lccc}
\hline & $\begin{array}{c}\text { Work trips (no. trips } \\
<2 \mathrm{~km}=10.719)\end{array}$ & $\begin{array}{c}\text { Study trips (no. trips } \\
<2 \mathrm{~km}=6.372)\end{array}$ & $\begin{array}{c}\text { Other trip purposes (no. } \\
\text { trips <2 km = 11.950) }\end{array}$ \\
\hline $\begin{array}{l}\text { Proportion of walking } \\
\text { trips (\%) }\end{array}$ & 66.5 & 72.3 & 65.8 \\
$\begin{array}{l}\text { Proportion of } \\
\text { motorized trips }(\%)\end{array}$ & 33.5 & 27.7 & 34.2 \\
\hline
\end{tabular}

\section{RESULTS}

The results of the selected models are shown in Table 4. The coefficients reflect the direction in which each variable influences the probability of walking. Positive coefficients indicate that a variable increases the likelihood of walking, whereas the negative indicate the opposite.

Table 4 shows that the probability of walking depends primarily on the trip distance. Short trips encourage walking. The estimated models also show that socioeconomic variables significantly influence the decision to walk. Factors such as car availability and high income reduce the tendency to choose walking.

The results show that built environment characteristics significantly influence the decision to walk (significance level of 5\%). Variables such as \% four-way intersections, transit availability and parking were the most influential variables in the analyzed models.

The purpose of the trip proved to be an important element. When analyzing the modal choice for work and study trips, it was observed that socioeconomic variables have greater predictive power in explaining the decision to walk than the built environment variables. However, built environment variables were shown to be strong predictors for other trip purposes.

Built environment characteristics that contribute to the choose walking for other trip purposes are: greater street connectivity, shops and services nearby and mixed land use patterns. Public parking supply and transit availability discourage walking, encouraging the use of motorized modes. A greater effect of the variables, land use mix and no. shops and services, was expected. This model result is probably related to the preferences of residents for specific shops and services. A qualitative study conducted in Porto Alegre by Larrañaga et al. [29] shows that preferences for shops or services strongly influence the decision to walk, particularly for higher income people. Respondents select the 'best' shop according to their personal valuation. This personal choice does not always coincide with the nearest alternative service. On the other hand, the signal of the variable block length was positive, contrary to expectations. This model behavior is probably due to two factors: (i) city topography and (ii) small variability of the average block length (Table 3). The studied neighborhoods have a hilly topography, which presumably influences walking decisions. This element was not considered in the analysis.

All explanatory variables were standardized to allow comparison of their effect on the response variable trips distance $<2 \mathrm{~km}$.

When analyzing work trips, \% four-way intersections was the most influent variable among built environment attributes. However, on study trips, Transit availability and Parking showed the highest impact. The influence of the variable Parking was contrary to the expected. A possible explanation is that most car parking spaces are free private parking in Porto Alegre [26]. Probably, a more detailed Parking variable is necessary to capture its real impact on the decision to walk. 


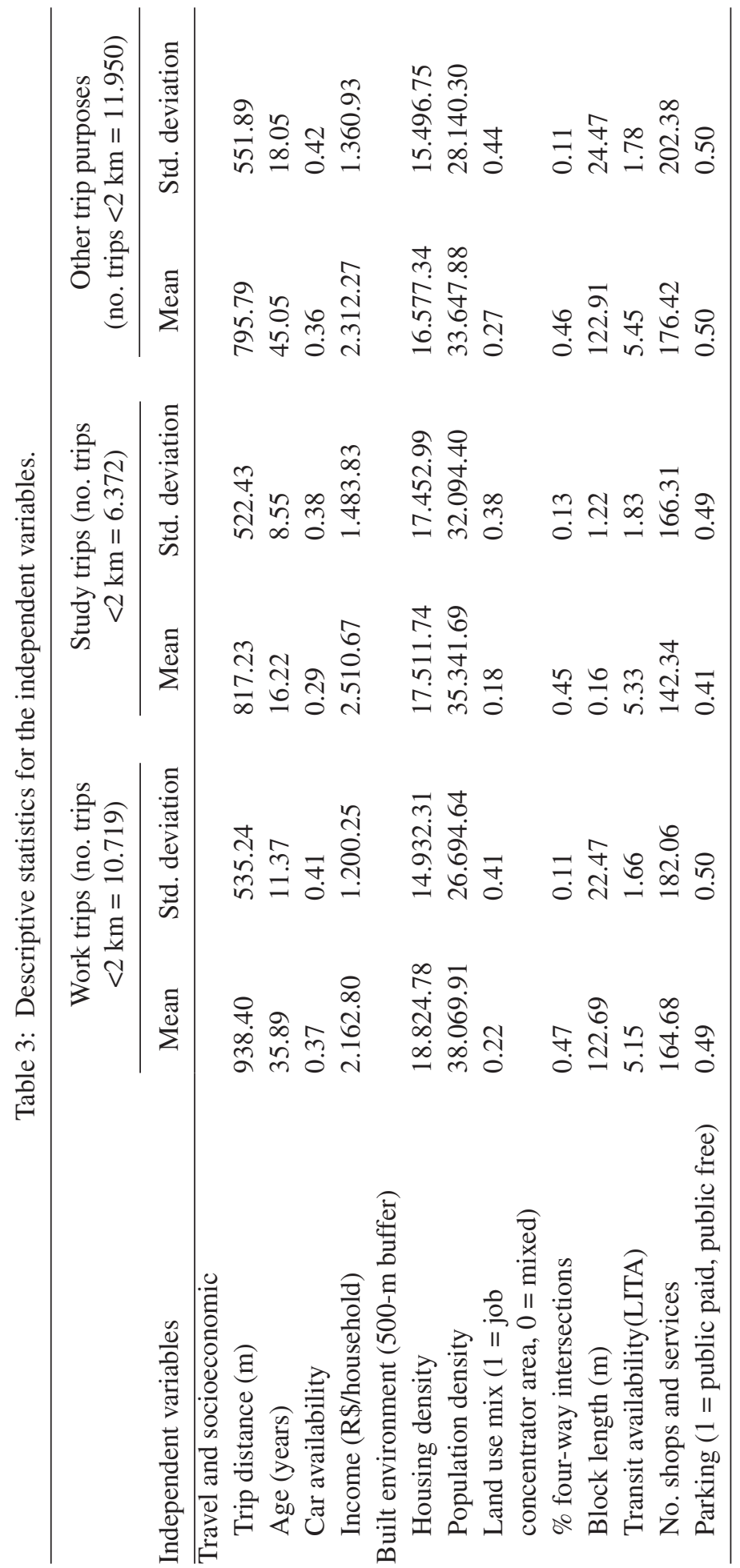


Table 4: Binomial logit models to predict the probability of walking.

\begin{tabular}{|c|c|c|c|c|c|c|}
\hline \multirow[b]{2}{*}{ Variables } & \multicolumn{2}{|c|}{ Work trips } & \multicolumn{2}{|c|}{ Study trips } & \multicolumn{2}{|c|}{ Other trip purposes } \\
\hline & Coefficient & p-value & Coefficient & p-value & Coefficient & $\mathrm{p}$-value \\
\hline \multicolumn{7}{|l|}{ Travel and socioeconomic } \\
\hline Trip distance (m) & -1.75 & 0.00 & -1.59 & 0.00 & -1.55 & 0.00 \\
\hline Age (years) & -0.19 & 0.00 & -0.10 & 0.00 & -0.25 & 0.00 \\
\hline Car availability & -0.42 & 0.00 & -1.43 & 0.00 & -0.27 & 0.00 \\
\hline $\begin{array}{l}\text { Income } \\
\text { (R\$/household) }\end{array}$ & -1.00 & 0.00 & -0.86 & 0.00 & -0.38 & 0.00 \\
\hline \multicolumn{7}{|l|}{ Built environment } \\
\hline $\begin{array}{l}\text { Land use mix } \\
(1=\text { job concentrator } \\
\text { area, } 0=\text { mixed })\end{array}$ & - & - & - & - & -0.15 & 0.00 \\
\hline $\begin{array}{l}\% \text { four-way } \\
\text { intersections }\end{array}$ & 0.40 & 0.00 & 0.20 & 0.00 & 0.42 & 0.00 \\
\hline Block length (m) & - & 0.00 & - & 0.00 & 0.24 & 0.00 \\
\hline $\begin{array}{l}\text { Transit availability } \\
\text { (LITA) }\end{array}$ & -0.204 & 0.00 & -0.49 & 0.00 & -0.28 & 0.00 \\
\hline $\begin{array}{l}\text { No. shops and } \\
\text { services }\end{array}$ & -0.32 & 0.00 & 0.01 & 0.00 & 0.15 & 0.03 \\
\hline $\begin{array}{l}\text { Parking }(1=\text { public } \\
\text { paid, public free })\end{array}$ & -0.15 & 0.00 & -0.49 & 0.00 & 0.39 & 0.00 \\
\hline \multirow[t]{2}{*}{ Constant } & 0.90 & 0.00 & 1.45 & 0.00 & 0.97 & 0.00 \\
\hline & \multicolumn{2}{|c|}{$\begin{array}{l}\text { No. observations } \\
\quad=10.759 \\
\text { Chi }^{2}(8)=5.672 \\
(p-\text { value }=0.00) \\
\text { Pseudo- }{ }^{2}=0.40\end{array}$} & \multicolumn{2}{|c|}{$\begin{array}{l}\text { No. observations } \\
\quad=6.372 \\
\text { Chi }^{2}(8)=4.122 \\
(\mathrm{p}-\text { value }=0.00) \\
\text { Pseudo- } \mathrm{R}^{2}=0.55\end{array}$} & \multicolumn{2}{|c|}{$\begin{array}{c}\text { No. observations } \\
=1.950 \\
\text { Chi }^{2}(10)=5.852 \\
(\mathrm{p}-\text { value }=0.00) \\
\text { Pseudo- } \mathrm{R}^{2}=0.38\end{array}$} \\
\hline
\end{tabular}

Table 4 presents the values of Mc-Fadden pseudo- $\mathrm{R}^{2}$ and Chi-square obtained in the estimation of the models. The values of pseudo- $\mathrm{R}^{2}$ are around 0.4 , showing a good fit for the logit model. The test results of the likelihood ratio, expressed by the value of Chi square, feature p-value associated with 0.000 . Therefore, it is concluded that there is strong evidence of association between variables.

\section{CONCLUSION}

Land use planning and urban design is an approach used to solve mobility problems, aimed at promoting non-motorized transport and the consequent reduction of automobile use. Studies in developed countries, mainly in the United States, suggest that elements of built environment are significant predictors of non-motorized travel, particularly walking trips. Factors such as population density, diversity of land use and street connectivity are associated with walking.

This study provides evidence that the built environment influences the decision to walk in Porto Alegre. The comparison of the estimated models for work trips, study and other trips showed that the effect of urban characteristics depends mainly on the purpose of the trip. On work and study trips, 
socioeconomic variables have greater predictive power in explaining the decision to walk than built environment variables. However, for other trip purposes, built environment variables were shown to be strong predictors.

The results showed that the effect of changing the built environment will be probably smaller on work and study trips than on other trip purposes. When considering work and study trips, the traveler personal attributes are the most important elements for choosing transport mode. However, greater street connectivity, which is associated with a greater supply of alternative routes, proved to be an important element to encourage walking. To promote walking, planners should pay special attention to urban projects, creating compact neighborhoods with mixed land use, grid street patterns and high street connectivity. The results showed that the likelihood of walking, for all trip purposes, depends mainly on the trip distance. Short distances encourage walking.

It was also observed that socioeconomic variables significantly influence the decision to walk. Factors such as car availability and high income reduce the tendency to choose the walk mode. It should be noted that the increase in car ownership observed in Brazilian cities in recent years may possibly reduce some of the positive consequences expected from land use planning and urban design.

Future studies could include characteristics of city topography, as well as residents' preferences in relation to the transport mode and neighborhood layout. Still, it would be interesting to analyze nonutilitarian trips, where walking is a form of exercise and not a mode of transport. The influence of built environment on utilitarian and non-utilitarian trips may be different, and both contribute to improve the quality of life.

\section{ACKNOWLEDGMENTS}

The authors thank Brazilian National Research Council (CNPq) for support through a research grant.

\section{REFERENCES}

[1] Baran, P., Rodríguez, D. \& Khattak, A., Space syntax and walking in a new urbanist and suburban neighborhoods. Journal of Urban Design, 13(1), pp. 5-28, 2008. doi: http://dx.doi. org/10.1080/13574800701803498

[2] Cao, X., Handy, S. \& Mokhtarian, P., The influences of the built environment and residential self-selection on pedestrian behavior, Tx. Transportation, 33(1), pp. 1-20, 2006. doi: http:// dx.doi.org/10.1007/s11116-005-7027-2

[3] Cervero, R. \& Duncan, M., Walking, bicycling, and urban landscapes: evidence from San Francisco Bay Area. American Journal of Public Health, 93(9), pp. 1478-1483, 2003. doi: http://dx.doi.org/10.2105/AJPH.93.9.1478

[4] Crane, R., The influence of urban form on travel: an interpretive review. Journal of Planning Literature, 15, pp. 3-23, 2000. doi: http://dx.doi.org/10.1177/08854120022092890

[5] Ewing, R. \& Cervero, R., Travel and the built environment. Journal of the American Planning Association, 76, pp. 265-294, 2010. doi: http://dx.doi.org/10.1080/01944361003766766

[6] Frank, L.D. \& Engelke, P.O., The built environment and human activity patterns: exploring the impacts of urban form on public health. Journal of Planning Literature, 16, pp. 202-218, 2001. doi: http://dx.doi.org/10.1177/08854120122093339

[7] Lee, C. \& Moudon, A.V., Correlates of walking for transportation or recreation purposes. Journal of Physical Activity and Health, 3(1), pp. 77-98, 2006.

[8] Denatran, www.denatran.gov.br/frota.htm, 2012.

[9] IBGE-Instituto Brasileiro de Geografia e Estatística, www.ibge.gov.br/home/estatistica/pesquisas/indicadores.php, 2012. 
[10] Vargas, J.C.B., Advanced capitalism and contemporary urban form: Porto Alegre in the XXI Century. Proc of the International Seminar on Urban Form 2007, ISUF: Ouro Preto, 2007.

[11] Cervero, R. \& Kockelman, K., Travel demand and the 3Ds: density, diversity, and design. Transportation Research D, 2(3), pp. 199-219, 1997. doi: http://dx.doi.org/10.1016/S1361-9209(97)00009-6

[12] Krizek, K., Operationalizing neighborhood accessibility for land use travel behavior research and regional modeling. Journal of Planning Education and Research, 22(3), pp. 270-287, 2003. doi: http://dx.doi.org/10.1177/0739456X02250315

[13] Boarnet, M.G., Greenwald, M. \& McMillan, T., Walking, urban design, and health: toward a cost-benefit analysis framework. Journal of Planning Education and Research, 27(3), pp. 341-358, 2008. doi: http://dx.doi.org/10.1177/0739456X07311073

[14] Chatman, D.G., Residential self-selection, the built environment, and nonwork travel: evidence using new data and methods. Environment and Planning A, 41(5), pp. 1072-1089, 2009. doi: http://dx.doi.org/10.1068/a4114

[15] Ewing, R., Greenwald, M.J., Zhang, M., Walters, J., Feldman, M., Cervero, R. \& Thomas, J., Measuring the impact of urban form and transit access on mixed use site trip generation ratesPortland pilot study. U.S. Environmental Protection Agency: Washington, DC, 2009.

[16] Frank, L.D., Kavage, S., Greenwald, M., Chapman, J. \& Bradley, M., I-places health \& climate enhancements and their application in King County. King County HealthScape: Seattle, WA, 2009.

[17] Naes, P., Residential location affects travel behavior-but how and why? The case of Copenhagen metropolitan area. Progress in Planning, 63(2), pp. 167-257, 2005. doi: http://dx.doi. org/10.1016/j.progress.2004.07.004

[18] Cervero, R. \& Radisch, C., Travel choices in pedestrian versus automobile oriented neighborhoods. Transport Policy, 3(3), pp. 127-141, 1996. doi: http://dx.doi.org/10.1016/0967-070X(96)00016-9

[19] Hess, P.M. \& Ong, P., Traditional neighborhoods and auto ownership. The Ralph and Goldy Lewis Center for Regional Policy Studies. Working Paper Series. Paper 37, 2001.

[20] Kitamura, R., Mokhtarian, P. \& Laidet, A., Micro-analysis of land use and travel in five neighborhoods in the San Francisco Bay Area. Transportation, 24, pp. 125-158, 1997. doi: http:// dx.doi.org/10.1023/A:1017959825565

[21] Handy, S.L. \& Clifton, K., Evaluating neighborhood accessibility: issues and methods using geographic information systems, Report SWUTC/00/167202-1. Southwest Region University Transportation Center, Center for Transportation Research, The University of Texas at Austin, 2000.

[22] Lawton, T.K., The urban environment effects and a discussion of travel time budget. Portland Transportation Summit: Portland, OR, 1997.

[23] Boarnet, M.G. \& Sarmiento, S., Can land-use policy really affect travel behaviour? A study of the link between non-work travel and land-use characteristics. Urban Studies, 35(7), pp. 1155-1169, 1998. doi: http://dx.doi.org/10.1080/0042098984538

[24] Greenwald, M.J., SACSIM modeling-elasticity results: draft. Unpublished manuscript, Fehr \& Peers Associates, Walnut Creek, CA, 2009.

[25] Targa, F. \& Clifton, K., The built environment and trip generation for non-motorized travel. Journal of Transportation and Statistics, 8(3), pp. 55-70, 2005.

[26] Secretaria de Mobilidade Urbana de Porto Alegre, Origin and Destination Survey of Porto Alegre - EDOM 2003. Technical Report, Porto Alegre, 2004.

[27] Rood, T., The local index of transit availability: an implementation manual. The Local Government Commission: Sacramento, CA, 1998.

[28] SPSS Inc., SPSS Base 10.0 Applications Guide. SPSS: Chicago, 1999.

[29] Larrañaga, A.M., Ribeiro, J.L.D. \& Cybis, H.B., Fatores que afetam as decisões individuais de realizar viagens a pé: um estudo qualitativo. Transportes, Rio de Janeiro, 2009. 